\title{
Arctic decadal variability: An auto-oscillatory system of heat and fresh water exchange
}

\author{
Dmitry S. Dukhovskoy ${ }^{1}$ \\ Institute of Marine Science, University of Alaska Fairbanks, Fairbanks, Alaska, USA \\ Mark A. Johnson \\ Institute of Marine Science, University of Alaska Fairbanks, Fairbanks, Alaska, USA
}

\author{
Andrey Proshutinsky \\ Physical Oceanography Department, Woods Hole Oceanographic Institution, Woods Hole, Massachusetts, USA \\ Received 7 November 2003; accepted 9 January 2004; published 5 February 2004.
}

[1] This paper presents a mechanism of decadal variability in the Artic Ocean-GIN Sea (Greenland, Iceland and Norwegian Seas) atmosphere-ice-ocean system. We hypothesize that Arctic variability is regulated by heat and freshwater exchange between the Arctic Ocean and the GIN Sea. The interaction between basins is weak during anticyclonic circulation regimes (low $\mathrm{AO} / \mathrm{NAO}$ ) and strong during cyclonic circulation regimes (high $\mathrm{AO} /$ NAO). Regime shifts are controlled by the system itself through oceanic and atmospheric gradients (dynamic height and surface air temperature) that increase during the anticyclonic regime and decrease during the cyclonic regime. This conceptual mechanism for Arctic decadal variability has been reproduced in a model experiment. Both model results and observational data support the suggested mechanism. INDEX TERMS: 4207 Oceanography: General: Arctic and Antarctic oceanography; 4215 Oceanography: General: Climate and interannual variability (3309); 4263 Oceanography: General: Ocean prediction; 4255 Oceanography: General: Numerical modeling; 4572 Oceanography: Physical: Upper ocean processes. Citation: Dukhovskoy, D. S., M. A. Johnson, and A. Proshutinsky (2004), Arctic decadal variability: An auto-oscillatory system of heat and fresh water exchange, Geophys. Res. Lett., 31, L03302, doi:10.1029/2003GL019023.

\section{Introduction}

[2] Decadal variability of the Arctic climate was identified using observations and models [e.g., Moritz et al., 2002], with specific features of Arctic climate behavior analyzed and described in numerous publications [e.g., Mysak and Venegas, 1998; Dickson et al., 2000; Zhang et al., 2003]. Proshutinsky and Johnson [1997] (hereafter P\&J) found that the Arctic atmosphere and ocean motion alternate between cyclonic and anticyclonic circulation regimes (CCR and ACCR, respectively) with each regime persisting from 4 to 8 years resulting in a period of $8-16$ years. Thompson and Wallace [1998] introduced the Arctic Oscillation (AO) index that describes the atmospheric processes associated with the two regimes (high AO or

\footnotetext{
${ }^{1}$ Now at Center for Ocean-Atmospheric Prediction Studies, Florida State University, Tallahassee, Florida, USA.

Copyright 2004 by the American Geophysical Union. 0094-8276/04/2003GL019023\$05.00
}

CCR, and low AO or ACCR). Another widely used index of climate variability is the NAO [Hurrell et al., 2003], and in many studies, observed changes in the Arctic climate system were analyzed assuming they are driven by the AO/NAO [Dickson et al., 2000; Rigor et al., 2002].

[3] Although the origin of Arctic climate decadal variability remains unclear, we assume that the $\mathrm{AO} /$ NAO are not only regulating the Arctic and North Atlantic climate variability but are also regulated by oceanic and sea ice conditions. Both wind-forced and thermohaline ocean circulation can actively interact with the atmosphere to produce coupled decadal and interdecadal climate variability [e.g., Latif and Barnett, 1996; Ikeda et al., 2001]. For the Arctic Ocean and the GIN Sea, Proshutinsky et al. [2002] (hereafter P2) suggested that decadal variability was regulated by fresh water (FW) and sensible heat fluxes between the basins. Here, we further describe these mechanisms and validate them with an idealized model and with observations. Our results show that the modeled Arctic system oscillates with periods from 10 to 15 years, depending on model internal parameters and external forcing (solar radiation, cloudiness, river runoff, etc.).

\section{System Description}

[4] The Arctic Ocean and the GIN Sea are viewed as an auto-oscillatory ice-ocean-atmosphere climate system. When the Arctic High prevails (ACCR or low AO/NAO), the interaction between basins is suppressed. The Arctic Ocean (mainly the Beaufort Gyre) accumulates FW and its potential energy increases, and the GIN Sea basin and its atmosphere accumulates internal energy (sensible heat). When the Icelandic Low dominates (CCR or high $\mathrm{AO} /$ $\mathrm{NAO}$ ), the basins strongly interact and release their energy. These two interaction states are described next.

\subsection{Weak Interaction State}

[5] During low AO/NAO, the interaction between the regions is weak: heat flux to the Arctic Ocean and FW flux to the GIN Sea are low. Low heat flux to the Arctic allows the arctic atmosphere to cool, SLP to increase and the anticyclone to become stronger (P\&J). This strengthens the Beaufort Gyre, increasing convergence of surface water and ice. FW is retained and potential energy accumulates in 


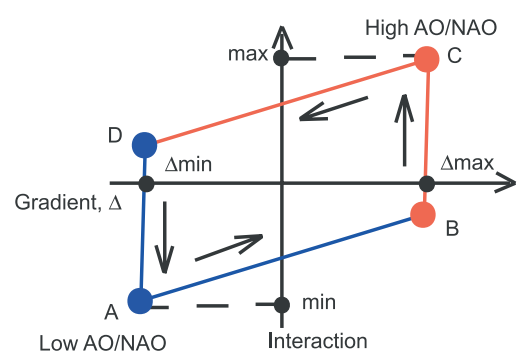

Figure 1. Hypothesized behavior of the Arctic-GIN Sea climate system. Abscissa is the between-basin gradient of SAT or dynamic height. Ordinate is the intensity of interaction between the basins, either FW or heat flux. Blue segments denote weak interaction and red segments intense interaction.

the Beaufort Gyre (P2). The upper Arctic Ocean contains more FW, and the atmosphere is colder, than average.

[6] With weak interaction, FW outflow to the GIN Sea is less than average. The reduction of fresh, buoyant surface water decreases water column stability and favors deep convection in the central Greenland Sea in winter. Strong convection and intense surface heat flux to the winter atmosphere cause positive surface air temperature (SAT) anomalies and intensification of cyclonic vorticity [Häkkinen, 1995; Mysak and Venegas, 1998].

[7] In this state, the Arctic is cooling and the upper ocean is freshening, and the GIN Sea region is warming. This leads to growth of SAT differences and dynamic height gradient (DHG) between the two regions. Strong gradients ultimately promote interaction such that intense heat flux to the Arctic warms the atmosphere and weakens the anticyclone [Serreze et al., 1997]. The ACCR then shifts to CCR (P\&J), and the system returns to the high $\mathrm{AO} / \mathrm{NAO}$ regime.

\subsection{Intense Interaction State}

[8] Strong gradients between the regions promote intense interaction that weakens anticyclonic circulation in the Beaufort Gyre and releases accumulated FW to the GIN Sea (P\&J, P2). The central Greenland Sea upper layer becomes fresher, increasing stability and suppressing deep convection [Aagaard and Carmack, 1994]. Without entrained oceanic heat from below, the mixed layer in the central Greenland Sea easily reaches the freezing point in winter, enhancing the ice cover [Häkkinen, 1995; Pawlowicz, 1995]. Both weak convection and ice cover reduce the heat flux to the winter atmosphere, which cools, and cyclonic vorticity decreases [Mysak and Venegas, 1998]. After several years of intense interaction, the SAT gradient and DHG have eroded, and the interaction fades. The system then rebuilds the gradients between regions.

\subsection{Gradients in the Ocean and Atmosphere}

[9] The behavior of our modeled system is controlled by DHG and SAT gradient. Segment AB (Figure 1) is characterized by weak interaction. During $\mathrm{AB}, \mathrm{SAT}$ in the Arctic stays cold and the Arctic High is strong. Weak interaction (low FW flux from Arctic), as mentioned above, favors deep convection in the Greenland Sea in winter. Surface heat flux to the winter atmosphere increases, warming the atmosphere over the Greenland Sea region and intensifying the Icelandic Low. The AO/NAO index increases. These changes in the Greenland Sea region are prominent and associated with increasing SAT and SLP gradients between the regions. After several years, both gradients reach their maximum (point B in Figure 1) and promote intense interaction.

[10] Segment BC, the strong interaction phase driven by large gradients, is characterized by high heat flux to the Arctic and high FW flux to the Greenland Sea. The Arctic atmosphere warms, so SLP decreases, and the anticyclonic regime switches to cyclonic. Because it takes a few years for the FW released from the Beaufort Gyre to reach the Greenland Sea, thermohaline changes in the central Greenland Sea are not prominent in the early years of intense interaction, so deep convection may continue and this region stays warm. During the $\mathrm{BC}$ interval, the $\mathrm{AO} / \mathrm{NAO}$ is increasing, SLP is decreasing in both regions, and gradients of SLP and SAT are decreasing.

[11] During CD, the intense FW flux from the Arctic freshens the upper layer in the Greenland Sea. Deep convection ceases, ice appears in the Greenland Gyre, the atmosphere starts cooling and SLP increases. The Icelandic Low weakens and the AO/NAO index decreases. During this interval, the Arctic stays warm from the high heat flux, and SLP remains low. SLP and SAT gradients continue to decrease.

[12] Interaction weakens over segment DA. Reduced heat flux from the Greenland Sea causes the Arctic atmosphere to cool, increasing SLP. The Arctic rebuilds the anticyclonic regime. Due to the large inertia of the ocean, the thermohaline structure in the Greenland Sea restores slowly. During the first few years of weak interaction, the central Greenland Sea water column remains stable and ice concentration stays relatively high. Thus the Greenland Sea region stays cold and the Icelandic Low remains weak. This interval is characterized by increasing SAT and SLP gradients, and a decreasing AO/NAO index. The system returns to point $\mathrm{A}$, finishing the cycle. Note that the low interaction phase (DAB) corresponds to low $\mathrm{AO} / \mathrm{NAO}$ with minimum at $\mathrm{A}$, and the high interaction phase $(\mathrm{BCD})$ corresponds to high $\mathrm{AO} / \mathrm{NAO}$ with maximum at $\mathrm{C}$.

\section{Model Experiment}

[13] To test the hypothesized auto-oscillatory behavior, we have used an idealized model with two modules: an

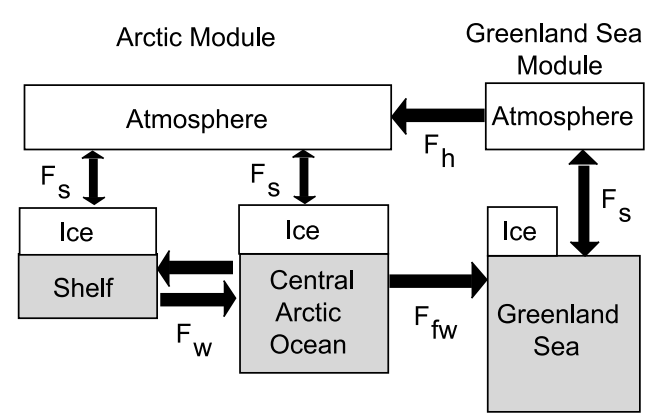

Figure 2. Schematic of the Arctic Ocean-Greenland Sea model system. $F_{\mathrm{s}}$ is surface heat flux, $\mathrm{F}_{\mathrm{w}}$ is water exchange between the Arctic Ocean model and Arctic shelf box model, $F_{f w}$ is the freshwater flux to the Greenland Sea model, $F_{h}$ is heat flux to the Arctic atmospheric model. 
(a)

(b)

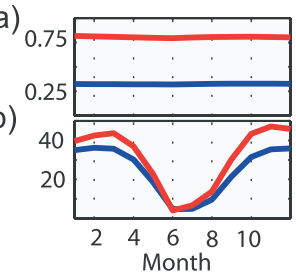

(d)

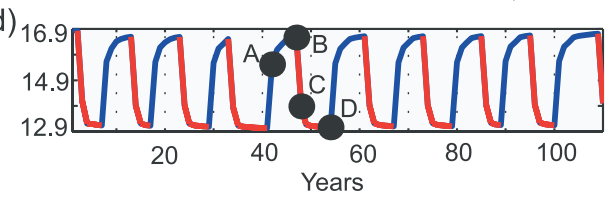

Figure 3. (a) Monthly outflow (Sv) from the upper $100 \mathrm{~m}$ of the Arctic Ocean during the weak interaction phase (blue) and strong interaction phase (red). (b) Similar to (a) but for the heat flux $\left(\mathrm{W} / \mathrm{m}^{2}\right)$. (c) Heat flux vs. gradient of dynamic height $\left(\Delta \mathrm{H}_{\text {dyn }}\right)$ for 110 years of simulated behavior (compare with Figure 1). (d) Annually averaged SAT difference $(\Delta T)$ for 110 years. Bullets denote system states shown on (c). On (c) and (d), red segments denote high $\mathrm{AO} /$ $\mathrm{NAO}$ years, blue low $\mathrm{AO} / \mathrm{NAO}$.

Arctic module and a Greenland Sea module (Figure 2). The Arctic module includes an Arctic Ocean model coupled to a thermodynamic sea ice model [Maykut, 1986], a sea-ice shelf model, and an atmospheric box model. The Arctic Ocean model is one-dimensional, three-layer and timedependent. This is the Arctic Ocean model of Björk [1989] with modified entrainment velocity, shelf inflow/ outflow and improved shelf - interior basin interaction. The three layers are: the mixed layer (ML), halocline layer (HL), and Atlantic layer (AL). The model describes deepening and shallowing of the ML, and temperature and salinity changes in the ML and HL. The characteristics of the Atlantic Layer do not change. The atmospheric box model estimates SAT from the total energy balance, with interannual variability induced by varying heat flux, $F_{h}$, from the Greenland Sea atmospheric box. $\mathrm{F}_{\mathrm{h}}$ is a function of SAT gradient $(\Delta \mathrm{T})$ between the Arctic and the Greenland Sea modules.

[14] The Greenland Sea ocean model is one-dimensional and time dependent and is, in general, similar to the Arctic Ocean model. There are several layers in the model following Swift [1986]. Deepening of the ML is driven by the equation Kato-Phillips [1969] and scales of Chapman [1998] for deep convection. The oceanic model is coupled to a thermodynamic sea ice model and an atmospheric model. The atmospheric model calculates SAT anomalies for computed surface heat flux. The Greenland Sea module describes the seasonal and interannual variability of the heat content of the GIN Sea region assuming that it is related to the air-sea surface heat flux. The air-sea heat flux, in turn, is determined by the intensity of deep convection in the Greenland gyre which is controlled by the amount of FW advected from the Arctic Ocean $\left(\mathrm{F}_{\mathrm{fw}}\right)$.

[15] The model was initialized with multiyear mean winter ocean temperature and salinity data [Environmental Working Group, 1998]. The forcing parameters in the model are: downwelling shortwave radiation, winds, river runoff, and Atlantic and Bering water fluxes. Forcing, including the air humidity, monthly ice/snow albedo, and cloudiness, have been prescribed with monthly means linearly interpo- lated into daily data [Gorshkov, 1980; Lindsay, 1998; Polyakov et al., 1999].

[16] The model has been run for 110 years, with the first 10 years spin-up. Different climate states are reproduced in the model by different rates of $\mathrm{F}_{\mathrm{fw}}$ and $\mathrm{F}_{\mathrm{h}}$ (Figures $3 \mathrm{a}$ and $3 b)$. As discussed in section 2, the DHG between the Arctic Ocean and the Greenland Sea increases when the interaction is weak, and the gradient decreases when the interaction is strong. In the model, the DHG between the Arctic Ocean and the Greenland Sea, $\Delta \mathrm{H}_{\mathrm{dyn}}$, controls the regime shifts via intense/weak interaction (Figure 1). When $\Delta \mathrm{H}_{\text {dyn }}$ reaches $\Delta_{\max }$ the intense interaction state is reproduced in the model, meaning high $\mathrm{F}_{\mathrm{fw}}$ and $\mathrm{F}_{\mathrm{h}}$ (red lines in Figures $3 \mathrm{a}$ and 3b). When $\Delta H_{\text {dyn }}$ approaches $\Delta_{\min }$ the low interaction state begins (blue lines in Figures $3 a$ and $3 b$ ). $\Delta_{\max }$ and $\Delta_{\min }$ are prescribed based on 20 year runs with low and high $\mathrm{F}_{\mathrm{fw}}$ and $\mathrm{F}_{\mathrm{h}}$ (Figures 3a and 3b) to find $\Delta_{\max }=0.173 \mathrm{~m}$ and $\Delta_{\min }=$ $0.164 \mathrm{~m}$.

\section{Results and Discussion}

[17] The simulated system behavior is similar to Figure 1. At point A (Figure 3c) the system is at the weak interaction stage with low AO/NAO. During low AO/NAO, the system shifts toward B as $\Delta \mathrm{H}_{\mathrm{dyn}}$ increases. At $\Delta_{\max }$, intense interaction drives the system toward C. Gradients then weaken until the system reaches $\mathrm{D}$, and the low $\mathrm{AO}$ regime resettles in the Arctic. The system returns to A.

[18] Each climate state in the ABCD loop in Figure 3c has two phases attributed to prominent changes either in the Arctic (DA and BC) or in the Greenland Sea (AB and CD). The model results show that the Arctic responds quickly to perturbations from the Greenland Sea (DA and BC each takes 1-2 years). However, changes in the Greenland Sea become noticeable $1-2$ years after the regime shift and evolve slowly ( $A B$ and $C D$ each take 3-4 years). Arctic changes are initiated by atmospheric heat advection, while Greenland Sea changes are driven by shifts in the thermohaline structure of the ocean. Obviously, atmospheric processes are faster.

[19] Computed $\Delta \mathrm{T}$ from simulated SAT in the Arctic and Greenland Sea boxes (Figure 3d) shows that during weak interaction, $\Delta \mathrm{T}$ increases (blue lines, Arctic cools and the Greenland Sea warms), and during intense interaction, $\Delta \mathrm{T}$ decreases (red lines, Arctic warms and the Greenland Sea cools). Bullets denote states of the system shown in Figure 3c. The period of simulated oscillations is 10 to 15 years.

[20] Regime shifts are controlled by FW and heat fluxes between the two basins that depend on atmospheric and oceanic gradients. To verify this, we examined SAT and SLP differences $(\Delta T, \Delta \mathrm{P})$ between the two basins, and the NAO (Figure 4) using observational data extracted from NCEP reanalysis data (http://www.cdc.noaa.gov). The records cover 1948-2001 and were averaged into winter means (November to March), then smoothed by a 5 -year moving average. $\Delta \mathrm{T}$ is computed between the central Greenland Sea $\left(74^{\circ} \mathrm{N}-76^{\circ} \mathrm{N}, 5^{\circ} \mathrm{W}-5^{\circ} \mathrm{E}\right)$ and the Central Arctic (poleward of $80^{\circ} \mathrm{N}$ ). $\Delta \mathrm{P}$ is between the Beaufort Gyre $\left(160^{\circ} \mathrm{W}-120^{\circ} \mathrm{W}, 74^{\circ} \mathrm{N}-84^{\circ} \mathrm{N}\right)$ and the central Greenland Sea.

[21] The $\Delta \mathrm{T}$ and $\Delta \mathrm{P}$ time series (Figures $4 \mathrm{a}$ and $4 \mathrm{~b}$ ) have a significant relation with the NAO (and respectively the 


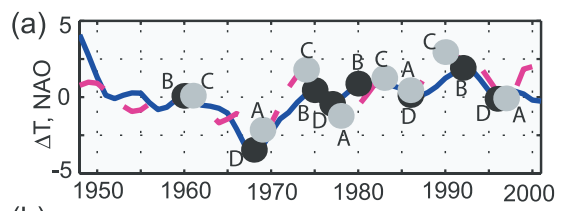

(b)
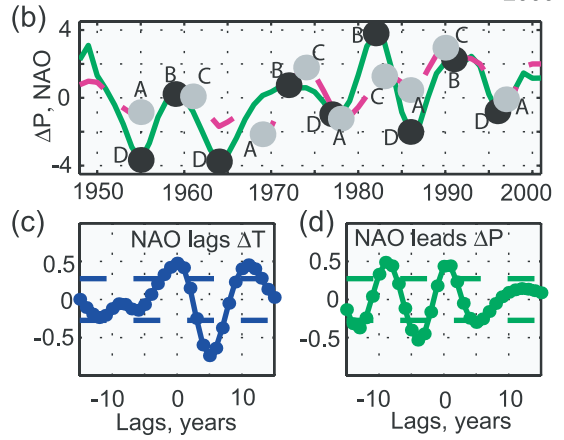

Figure 4. Observational data. (a) Time series of SAT difference $(\Delta T)$ between central Arctic and central Greenland Sea (blue solid) and NAO (magenta dashed). Means are removed, and 5-year smoothing was applied. A and $\mathrm{C}$ mark the low and high NAO (gray bullets), and B and D the low and high gradients (black bullets). Letters correspond to the system state shown in Figure 1. (b) Same as (a) but for the SLP difference $(\Delta \mathrm{P})$ between the Beaufort Gyre and central Greenland Sea (green solid). (c) Cross-correlation between $\Delta \mathrm{T}$ and NAO. Dashed lines denote $98 \%$ confidence interval for white noise cross-correlation coefficients. (d) Same as (c) but for $\Delta \mathrm{P}$ and NAO.

AO, not shown). There is a positive cross-correlation between the NAO and $\Delta \mathrm{P}, \Delta \mathrm{T}$ around 0 lag ( $\pm 1-2$ years), negative cross-correlation at 3-7 years lag and again positive at 8-12 years lag (Figures $4 \mathrm{c}$ and $4 \mathrm{~d}$ ). Thus maxima (minima) of $\Delta \mathrm{T}, \Delta \mathrm{P}$, and NAO all occur within a few years of each other. Then, in $\sim 3-7$ years, $\Delta \mathrm{T}$ and $\Delta \mathrm{P}$ reach their minima (maxima) and in 8-12 years, both differences are again maximal (minimal), finishing a decadal cycle. The behavior of time series of gradients in observed SAT, observed SLP, and the NAO index agree remarkably well with our model behavior. The sequence of maxima and minima of $\Delta \mathrm{T}, \Delta \mathrm{P}$ (black bullets in Figures $4 \mathrm{a}$ and $4 \mathrm{~b}$ ), and NAO (grey bullets) found in the time series is similar to that suggested in our mechanism (Figure 1). For better visualization, the maxima and minima have been marked by letters in Figures $4 \mathrm{a}$ and $4 \mathrm{~b}$ according to the system state in Figure 1. Note that the time interval between points $\mathrm{B}$ and $\mathrm{C}$ and points $\mathrm{D}$ and $\mathrm{A}$ are mostly 1-2 years long while the time between points $C$ and $D$ and points $\mathrm{A}$ and $\mathrm{B}$ are $3-6$ years, in agreement with the model results (Figures 3c and 3d).

[22] In conclusion, the suggested mechanism of decadal variability for the Arctic and GIN Sea is based on the assumption that FW and heat exchange determine the climate state in both regions. The intensity of the exchange is controlled by oceanic and atmospheric gradients. This is supported by both results from an idealized model and by observations. The strength of the correlations between the $\mathrm{AO} / \mathrm{NAO}$ and gradients of observed parameters at multiyear lags may provide a measure of predictability for decadal variations in the Arctic climate system.
[23] Acknowledgments. This research has been supported by the National Science Foundation and by the International Arctic Research Center, University of Alaska Fairbanks, under auspices of the United States National Science Foundation and from the Alaska Sea Grant through the Center for Global Change, University of Alaska Fairbanks.

\section{References}

Aagaard, K., and E. C. Carmack (1994), The Arctic and climate: A perspective, in Polar Oceans and Their Role in Shaping the Global Environment, edited by O. M. Johannessen et al., pp. 4-20, Geophys. Monogr. Ser., AGU, Washington, D. C.

Björk, G. (1989), A one-dimensional time-dependent model for the vertical stratification of the upper Arctic Ocean, J. Phys. Oceanogr., 19, 52-67.

Chapman, D. C. (1998), Setting the scales of the ocean response to isolated convection, J. Phys. Ocean., 28, 606-620.

Dickson, R. R., T. J. Osborn, J. W. Hurrell, J. Meincke, J. Blindheim, B. Adlandsvik, T. Vinje, G. Alekseev, and W. Maslowski (2000), The Arctic Ocean response to the North Atlantic Oscillation, J. Climate, 13, $2671-2696$.

Environmental Working Group (EWG) (1998), Joint U. S. Russian Atlas of the Arctic Ocean for the Winter/Summer Period [CD-ROM], Natl. Snow and Ice Data Cent., Boulder, Colo.

Gorshkov, S. G. (1980), Atlas of Oceans: Arctic Ocean (in Russian), 199 p., Mil. Def., Moscow.

Häkkinen, S. (1995), Simulated interannual variability of the Greenland Sea deep water formation and its connection to surface forcing, J. Geophys. Res., 100(C3), 4761-4770.

Hurrell, J. W., Y. Kushnir, G. Ottersen, and M. Visbeck (Eds.) (2003), The North Atlantic Oscillation climatic significance and environmental impact, 279 pp., AGU, Washington, D. C.

Ikeda, M., J. Wang, and J.-P. Zhao (2001), Hypersensitive decadal oscillations in the Arctic/subarctic climate, Geophys. Res. Lett., 28(7), 1275-1278.

Kato, H., and O. M. Phillips (1969), On the penetration of a turbulent layer into a stratified fluid, J. Fluid Mech., 37, 643-655.

Latif, M., and T. P. Barnett (1996), Decadal variability over the North Pacific and North America: Dynamics and predictability, J. Climate, 9, $2407-2423$.

Lindsay, R. W. (1998), Temporal variability of the energy balance of thick Arctic pack ice, J. Climate, 11, 313-333.

Maykut, G. A. (1986), The surface heat and mass balance, in The Geophysics of Sea Ice, edited by N. Untersteiner, pp. 395-463, Plenum Press.

Moritz, R. E., C. M. Bitz, and E. J. Steig (2002), Dynamics of recent climate change, Science, 297, 1497-1502.

Mysak, L. A., and S. A. Venegas (1998), Decadal climate oscillations in the Arctic: A new feedback loop for atmospheric-ice-ocean interactions, Geophys. Res. Lett., 25(19), 3607-3610.

Pawlowicz, R. (1995), A note on seasonal cycles of temperature and salinity in the upper waters of the Greenland Sea Gyre from historical data, J. Geophys. Res., 100(C3), 4715-4726.

Polyakov, I. V., A. Y. Proshutinsky, and M. A. Johnson (1999), Seasonal cycles in two regimes of Arctic climate, J. Geophys. Res., 104(C11), $25,761-25,788$

Proshutinsky, A., R. H. Bourke, and F. A. McLaughlin (2002), The role of the Beaufort Gyre in Arctic climate variability: Seasonal to decadal climate scales, Geophys. Res. Lett., 29(23), 2100, doi:10.1029/ 2002GL015847.

Proshutinsky, A. Y., and M. A. Johnson (1997), Two circulation regimes of the wind-driven Arctic Ocean, J. Geophys. Res., 102(C6), 12,49312,514 .

Rigor, I. G., J. M. Wallace, and R. Colony (2002), Response of sea ice to the Arctic Oscillation, J. Climate, 15, 2648-2663.

Serreze, M. C., F. Carse, and R. G. Barry (1997), Icelandic Low cyclone activity: Climatological features, linkages with the NAO, and relationships with recent changes in the Northern Hemisphere circulation, J. Climate, 10, 453-464.

Swift, J. H. (1986), The Arctic waters, in The Nordic Seas, edited by B. G. Hurdle, pp. 129-153, Springer-Verlag, New York.

Thompson, D. W. J., and J. M. Wallace (1998), The Arctic Oscillation signature in the wintertime geopotential height and temperature fields, Geophys. Res. Lett., 25, 1297-1300.

Zhang, X., M. Ikeda, and J. E. Walsh (2003), Arctic sea ice and freshwater changes driven by the atmospheric leading mode in a coupled ice-ocean model, J. Climate, 16, 2159-2177.

D. S. Dukhovskoy, Center for Ocean-Atmospheric Prediction Studies, Florida State University, Tallahassee, FL, USA. (ddmitry@coaps.fsu.edu) M. A. Johnson, Institute of Marine Science, University of Alaska Fairbanks, Fairbanks, AK, USA.

A. Proshutinsky, Physical Oceanography Department, Woods Hole Oceanographic Institution, Woods Hole, MA, USA. 